\title{
ENSINO DE GEOGRAFIA, ESPAÇO E LINGUAGEM CARTOGRÁFICA
}

\author{
Prof. Dr. Denis Richter \\ Curso de Geografia da UFMS \\ Rodovia MS 134, Km 03, CEP 79750-000 - Nova Andradina (MS), Brasil \\ Tel./Fax: (+ 55 67) 34490500 - drichter78@gmail.com \\ Profa. Dra. Fátima Aparecida Dias Gomes Marin \\ fatimadiasgomes@gmail.com \\ Profa. Dra. Mônica Modesta Santos Decanini \\ monca@fct.unesp.br
}

\begin{abstract}
RESUMO
O ensino de Geografia precisa encontrar e fortalecer sua presença no processo de ensino-aprendizagem ao longo da Educação Básica. Para isso, é fundamental a proximidade dessa disciplina escolar com os conceitos geográficos que dão sentido e valorizam a participação da Geografia no entendimento da organização da sociedade. No entanto, para que a análise espacial esteja mais presente no trabalho escolar, consideramos necessário a inserção de práticas pedagógicas que articulem os conceitos com uma linguagem específica, neste caso a cartográfica. De todos os produtos cartográficos que estão presentes no ambiente escolar o mapa mental tem sido uma proposta muito pertinente para desenvolver o raciocínio geográfico. Desse modo, além de interpretar os processos que interferem na produção do espaço o aluno tem condições de construir uma linguagem espacial que expresse os diversos contextos da realidade sob a ótica espacial.
\end{abstract}

Palavras-chave:Ensino de Geografia, espaço geográfico, linguagem cartográfica, mapas mentais.

\begin{abstract}
The geographical teaching must find and strengthen its presence in teaching-learning throughout basic education.For this, is crucial that school discipline be closer with geographical concepts that give meaning and value the participation of geography in understanding the society's organization. However, for the spatial analysis be more present in school work, we consider the inclusion of appropriate pedagogical practices that express the concepts with a specific language, in this case the language mapping. One of all over the cartographical products that are present in the schools, the mental map has been a very useful proposal to develop the geographic reasoning. In addition to interpreting the processes that affect the production of space, the students should be able to build a spatial language that expresses the different contexts of reality from the space perspective.
\end{abstract}

Key words: Geography education, geographic area, language mapping, mind maps.

\section{RESUMEN}

La enseñanza de la geografía debe encontrar y fortalecer su presencia en la enseñanza-aprendizaje en la educación básica. Para ello, es fundamental que la proximidad de disciplina escolar con los conceptos geográficos que dan sentido y valor de la participación de la geografía en la comprensión de la organización de la sociedad. Sin embargo, para el análisis espacial está más presente en su trabajo escolar, consideramos que la inclusión de las prácticas pedagógicas adecuadas que expresan los conceptos con un lenguaje específico, en este caso el mapa. De todos los productos cartográficos que están presentes en el mapa mental de la escuela ha sido una propuesta muy útil para desarrollar el razonamiento geográfico. Así, además de la interpretación de los procesos que afectan la producción del espacio que el estudiante es capaz de construir un lenguaje espacial que expresa los diferentes contextos de la realidad desde la perspectiva del espacio.

Palabras clave: Enseñanza de la geografía, espacio geográfico, lenguaje cartográfíca, mapas mentales.

\section{INTRODUÇÃO}

Muitos programas curriculares de Geografia, de escolas públicas e particulares, dos três níveis de ensino (Fundamental, Médio e Superior), têm como propósito a busca por ampliar o debate e salientar a importância de construir um olhar mais atento para as transformações que ocorrem no espaço, seja de cunho político, cultural, econômico, natural, social, ambiental, individual, coletivo, entre outros.

No entanto, será que esses objetivos são/estão materializados nas práticas sociais dos indivíduos que freqüentaram os bancos escolares? Como a Geografia tem se relacionado com um dos seus 
principais conceitos teóricos, que é o espaço geográfico? Onde se encontra o conceito de espaço no processo de ensino-aprendizagem de Geografia na Educação Básica? De que modo o professor pode articular a linguagem cartográfica com o estudo da análise espacial? E qual a sua contribuição para a formação do indivíduo?

São questionamentos como esses que orientam o percurso que pretendemos fazer a respeito da prática pedagógica de Geografia. Muito mais do que reescrevermos a História do ensino de Geografia, almejamos apresentar algumas reflexões que permitam avançar nos estudos relacionados a prática escolar dessa ciência.

Mesmo assim, consideramos necessário esclarecer que inúmeros problemas e desafios do ensino de Geografia, apontados por autores como Cavalcanti (1998), Callai (2000), Kaercher (2002), que realizaram um levantamento criterioso sobre o cotidiano escolar, ainda fazem parte da realidade de muitas escolas no Brasil. Desde o uso descritivo dos conteúdos geográficos, que foi subserviente a manipulação das políticas do Estado, como por exemplo, no tempo da ditadura brasileira (19641989), até no desenvolvimento a-crítico desses conteúdos, que serviam para controlar as reflexões sobre o próprio sistema, o ensino de Geografia foi fortemente marcado por uma característica de saber desnecessário e passageiro. Em decorrência desses fatos, não é de se estranhar que muitas pessoas, nos dias de hoje, entendam que essa disciplina escolar só possui sentido para a realização de concursos, como o vestibular. Se isso ocorreu, foi em razão dos elementos e dos fatores históricos que contribuíram para formar e caracterizar esta ciência, e que não possibilitaram a construção de um saber científico mais coadunado com os problemas que interferem na sociedade.

Esses pontos contextualizam a necessidade de procurarmos, cada vez mais, práticas escolares que possam sobrepujar essa realidade e modificar, significativamente, o ensino de Geografia. Acreditamos que a formação escolar dos indivíduos deve estar embasada na transmissão de saberes que contribua na construção de uma reflexão crítica e, principalmente, transformadora. De nada adianta participarmos da escola se essa instituição não fornece os elementos indispensáveis para que os alunos possam compreender o meio em que vivem, correlacionar os fatos e os fenômenos que interferem nas estruturas sócio-econômico-culturais, e construir bases para forjar a transformação.

Em contrapartida, os debates teóricos presentes nas faculdades de Geografia se desenvolveram consideravelmente nos últimos anos. Desde que o movimento de renovação da Geografia (década de 1970-1980) projetou novos campos de atuação dessa ciência e, ao mesmo tempo, fortaleceu sua consistência enquanto área acadêmica na produção científica, a Geografia universitária obteve um crescimento que pode ser comprovado pelo aumento dos cursos de graduação e de pós-graduação, pelas inúmeras publicações acadêmicas e na participação mais atuante em diversos setores da sociedade.

O descompasso existente entre essas duas instâncias na Geografia, a escolar e a acadêmica, representa um sério problema por indicar que a mudança tão necessária e desejada ocorre parcialmente. Fato que revela a fraqueza do ensino de Geografia perante os diversos desafios que esta ciência já enfrentou. Podemos observar essa realidade na pesquisa de Kaercher (2004), quando esse autor encontra elementos marcantes que expressam a divisão entre a Geografia que se propaga nos cursos de graduação e a Geografia que se pratica nas salas de aula da Educação Básica. Leituras como essas contribuem para reforçar a necessidade de rever o atual estágio em que se encontra o ensino de Geografia.

De acordo com esses apontamentos iniciais, entendemos que o conhecimento científico desenvolvido pela Geografia, ao longo dos anos, deve fazer parte do ambiente escolar. As interpretações mais criteriosas da produção do espaço, articuladas com o uso dos conceitos geográficos, são elementos fundamentais que dão sentido ao saber ensinado por essa disciplina. Muito mais do que apenas ampliar o vocabulário do aluno, com a inserção de palavras como: espaço geográfico, território, região, lugar, redes, paisagem etc, o trabalho didático de Geografia deve pautar pela relação desses saberes científicos na observação e compreensão do cotidiano. Desse modo, o aluno 
poderá utilizar o conhecimento geográfico para interpretar os diversos contextos que atuam e são responsáveis pela produção do espaço e que, indiretamente, afetam sobre sua própria vivência.

\section{O ENSINO DE GEOGRAFIA É O ENSINO DO ESPAÇO GEOGRÁFICO?}

Ao longo do processo de institucionalização da Geografia, muitas abordagens teórico-metodológicas já influenciaram esta ciência. De uma perspectiva científica mais preocupada em descrever o espaço, passou para a compreensão do espaço como sendo resultado de uma produção humana. De uma ciência mais submissa ao Estado, passou para uma atuação mais presente nas lutas sociais e contestadoras das inúmeras desigualdades produzidas pelo sistema capitalista. De uma disciplina que se estruturava na dicotomia entre o físico e o humano, passou para a construção de um olhar mais integrado e sistêmico às relações sociedade-natureza. Essas mudanças significaram a formação de uma Geografia capaz de atuar em diversas áreas, desde questões referentes ao meio ambiente, a população, aos recursos naturais, a economia, a política, a cultura, a Educação, entre outros (LACOSTE, 1988; CLAVAL, 2002; e MOREIRA, 2007).

De todas essas áreas, a Educação tem sido um lugar de forte atuação da Geografia, principalmente por fazer parte como um campo disciplinar presente na Educação Básica no Brasil. Entendemos que essa situação representa um importante papel para essa ciência no processo de desenvolvimento cultural e social dos indivíduos. Nesse sentido, ao realizarmos discussões sobre a relação entre a Geografia e a Educação, temos a possibilidade de encontrar caminhos que possam contribuir para a formação de indivíduos mais atentos as questões espaciais e, ao mesmo tempo, capazes de transformar seu meio.

Diante dessas considerações, nos cabe retornar a um dos questionamentos iniciais desse texto: como o ensino de Geografia tem se relacionado com o conceito de espaço, que representa a sua identidade em referência as outras ciências?

Se é correto dizermos que a Geografia produz uma leitura espacial da realidade, podemos dizer, também, que o espaço dá sentido a Geografia. Ao buscarmos estudos que contextualizam a construção histórica dessa área do saber, encontramos um ponto em comum entre os diversos autores que discorrem sobre esse tema, como Lacoste (1988), Claval (2002), Santos (2002), e Moreira (2007). Para eles, a Geografia inicia quando os homens buscam explicações sobre os lugares que vivem ou pelos caminhos percorridos entre esses lugares habitados. Historicamente, o resultado dessas indagações foi a produção de um conhecimento que fez um elogio à descrição, como método de compreender as estruturas que compõem o meio e, ao mesmo tempo, o reflexo de uma prática científica embasada na perspectiva analítica.

Essa situação representa que o peso histórico sobre a prática de descrever o espaço é muito grande, ou seja, bem maior do que a abordagem atual que valoriza não só a descrição, mas a interpretação integrada dos fatos que influenciam na produção do espaço. Portanto, se hoje ainda é possível encontrarmos situações que remetem o ensino de Geografia a seus períodos mais antigos, isto é conseqüência do passado que construiu os alicerces dessa ciência numa base positivista e analítica.

Não queremos, com isso, dizer que a possibilidade de alterar esse quadro é nula. Pelo contrário, buscamos com essa leitura histórica compreender quais são os motivos que ainda mantém o ensino de Geografia marcado, muitas vezes, pelas ações descritivas e a-críticas. Ao termos consciência da gênese dessa questão e de reconhecermos os elementos que envolvem o trabalho docente, é que teremos condições de superar essa situação.

De acordo com essas idéias podemos desenvolver alguns questionamentos, como por exemplo: quais são os contextos que podem explicar o distanciamento do ensino de Geografia com a análise espacial? Para respondermos isso, as contribuições de Massey (2008) são pertinentes. Essa autora faz significativos apontamentos de como o conceito de espaço foi tratado pela sociedade. Para ela, a perspectiva do capital buscou sempre enaltecer o tempo como principal conceito, por encontrar nele elementos que pudessem colaborar no ato produtivo e reprodutivo do próprio capital,

Mercator - volume 9, número 20, 2010: set./dez. 
tanto como sistema econômico ou cultural. Em outra observação, a autora destaca que em muitos estudos científicos existe uma supervalorização do tempo. Isso se deve pelo fato da História ser interpretada como objeto científico competente para compreender a própria sociedade e, também, da maneira como foi analisado o tempo - dinâmico, aberto e flexível -, enquanto que o espaço foi considerado o contrário disso.

Mas, uma ressalva é necessária para esclarecermos que leitura é feita sobre a relação entre os conceitos de tempo e espaço:

Há uma distinção que precisa ser feita desde o início. Foi argumentado que, pelo menos nos últimos séculos, o espaço tem sido menos valorizado e tem recebido menos atenção do que o tempo [...]. Freqüentemente, advoga-se a "priorização do tempo sobre espaço", e isto foi comentado e severamente criticado por muitos. Não é esta, no entanto, minha preocupação aqui. O que me preocupa é o modo como imaginamos o espaço. Algumas vezes o caráter problemático dessa imaginação resulta, provavelmente, da despriorização - a conceituação de espaço como uma reflexão a posteriori, como um resíduo do tempo. No entando, não se pode dizer que os primeiros pensadores estruturalistas deram prioridade ao tempo, e ainda, ou assim eu devo argumentar, o efeito de sua abordagem foi uma imaginação do espaço altamente problemática. (MASSEY, 2008, p. 41)

Para galgar os problemas evidenciados, a mesma autora enfatiza algumas proposições que devem ser levantadas ao se questionar sobre a importância do conceito de espaço nos estudos da sociedade. Primeiro, espaço como produto das interrelações global-local; segundo, espaço como esfera da multiplicidade, local onde as diferentes trajetórias coexistem, sem espaço não há multiplicidade e vice-versa; e terceiro, espaço como elemento em constante construção.

Nessa valorização do conceito de espaço, Moreira (2007) também produz algumas análises interessantes. $\mathrm{O}$ autor indica que a solução da Geografia em estabelecer no espaço a resposta para todas as suas dúvidas ou demonstrar segurança frente as questões científicas, não resolve por completo. Nem sempre a localização exata de fenômenos compreende a complexidade de um processo, já que o mesmo pode não ter uma base exata, matemática. Pode haver uma desordem.

Para resolver essa situação, o referido autor indica uma postura que devemos tomar:

De certo modo, isso significa resgatar toda a tradição da geografia como estudo da relação homem-meio, vista agora não mais como embutida numa arquitetura de tempo-espaço matemático-mecânico, em que até hoje teoricamente foi posta, mas na arquitetura holista da espacialidade diferencial, cujo resultado mais claro é fazer do espaço um tecido formado pelo complexo de todas as relações que intervêm na transformação da superfície terrestre como o verdadeiro espaço da sociedade humana. (MOREIRA, 2007, p. 129).

Na concepção de Santos (2002), os questionamentos se instalam na necessidade de reconhecermos a função que o conceito de espaço possui para a Geografia. Sua crítica está no fato de que muitas ciências se utilizam dessa categoria para se expressar e expressar suas idéias, mas sem ao certo saber do que se trata. O uso do termo espaço tornou-se tão "comum" nas academias que ficou difícil traduzir ou interpretar seu real significado (espaço mental, espaço sideral, espaço social, espaço geopolítico, entre outros). Por conta desta dificuldade, acabamos mais por descrever o espaço do que conceituá-lo. Esse mesmo autor complementa suas idéias ao destacar que os primeiros textos que começavam a expressar o papel da Geografia, tinham como questão central o "onde(?)". Para Santos (id.) essa foi e é a grande pergunta da Geografia e a representação do seu trabalho ímpar, que não pode ser esquecido ao desenvolvermos sua prática científica ou escolar.

Ao recordarmos as preocupações de Santos (1978) sobre o conceito de espaço, registrado num momento em que haviam leituras que consideravam o papel da Geografia como uma ciência mais coadunada com as perspectivas tecnicistas e pragmáticas, sua análise pautava-se pela superação desta condição para o exercício de uma Geografia mais atenuada com a idéia do espaço humano ou 
espaço social. Essa posição amplia, demasiadamente, a possibilidade de definição de espaço, pois ele se estrutura na multiplicidade.

Entretanto, Santos (id.) apresenta uma interpretação do espaço geográfico, que se refere:

O espaço deve ser considerado como um conjunto de relações realizadas através de funções e de formas que se apresentam como testemunho de uma história escrita por processos do passado e do presente. Isto é, o espaço se define como um conjunto de formas representativas de relações sociais do passado e do presente e por uma estrutura representada por relações sociais que estão acontecendo diante dos nossos olhos e que se manifestam através de processos e funções. O espaço é, então, um verdadeiro campo de forças cuja aceleração é desigual. Daí porque a evolução espacial não se faz de forma idêntica em todos os lugares. (p. 122)

Nesse sentido, consideramos fundamental que o trabalho escolar de Geografia utilize essas categorias do espaço (forma, função, estrutura e processo) para que as leituras e as interpretações sobre as mais diferentes paisagens, contextos e fenômenos possam ser ensinados aos alunos de modo mais científico e coerente com os elementos que são responsáveis pela sua produção.

A postura que muitos autores assumem ao destacar a contribuição da análise espacial para compreender o mundo, está diretamente relacionada a construção de uma prática de interpretação da sociedade, em outras palavras, trata-se de uma forma de ler o mundo (CALLAI, 2005). Dentre todas as possibilidades de leitura do espaço que podemos fazer, presente na análise da paisagem, no estudo dos diferentes territórios, na identificação das regiões ou na investigação sobre a produção do lugar, temos condições de destacarmos a importante relação existente entre as práticas de leitura com a formação de uma linguagem, nesse caso uma linguagem espacial e que pode ser chamada de cartográfica.

O que queremos salientar aqui é a existência da forte proximidade entre a tríade ensino de Geografia - espaço - linguagem cartográfica. Esses três elementos devem fazer parte das práticas escolares que procuram desenvolver uma capacidade no indivíduo de analisar o mundo sob a perspectiva espacial. O resultado desse processo pode ser observado no raciocínio geográfico, isto é, na capacidade intelectual do indivíduo para interpretar os elementos e os fenômenos que compõe e que interferem na produção do mundo, a partir da ótica espacial.

\section{O USO DA LINGUAGEM CARTOGRÁFICA NO ENSINO DE GEOGRAFIA: UM CAMINHO PARA COMPREENDER O ESPAÇO}

A presença dos produtos cartográficos nas práticas escolares de Geografia sempre foi marcante, tanto que existe uma certa associação do mapa como objeto simbólico e representante do trabalho desenvolvido pela Geografia na Educação Básica. Nesse sentido, podemos destacar incentivo que Katuta (2007) faz ao salientar a importante integração das diversas linguagens_no ensino de Geografia. Essa pesquisadora destaca que as linguagem devem ser incorporadas ao processo de aprendizagem de modo a provocar nos alunos reflexões investigativas, ao invés de simplesmente representarem um fim em si mesmas ou de se tornarem somente mais um recurso que venha ilustrar ou apenas dinamizar as aulas dessa disciplina. De acordo com essas considerações, entendemos que o docente precisa desenvolver metodologias para que os alunos tenham a possibilidade de raciocinar uma análise espacial, a partir do uso e da produção das linguagens - principalmente no que tange aos produtos cartográficos.

Ao analisarmos a História da produção dos mapas, podemos observar que eles foram desenvolvidos no momento que a precisão matemática era fundamental. Isso explica por que os cartógrafos da época rejeitaram novas formas de representação que fugissem de uma certeza cartesiana ou que não apresentassem um rigor científico na sua produção (GOMES, 2004). Contudo, nos

Mercator - volume 9, número 20, 2010: set./dez. 
dias atuais muitos estudiosos da área da Cartografia e da representação espacial têm observado com mais cuidado novas formas da produção dos mapas. Para aprofundar esse tema, as contribuições de Harley (1991) são válidas:

Para poderem estudar todos esses novos aspectos, os historiadores da cartografia estão adotando teorias provenientes das ciências humanas e sociais. Deixou-se de acreditar, por exemplo, na pretensa supremacia do sistema de representação numérica do mundo. Também já não se crê que os mapas modernos, inclusive os objetivos mediante o concurso do satélite Landstat e dos computadores, estejam à margem das maquinações do poder. Tal como o mapa de uma cosmografia indiana ou qualquer representação asteca do Universo, as cartas geográficas por satélite não deixam de ser construções sociais. Começamos a compreender que a cartografia moderna é fruto de uma empresa global, uma forma de poder/saber mesclada às principais transformações produzidas na história do mundo, criada e recebida por agentes humanos, explorada pelas elites para exprimir uma visão ideológica do mundo. (p. 09)

Se o uso da linguagem cartográfica pode contribuir para questionar as formações rígidas que estruturam, muitas vezes, o saber, precisamos relacionar esse meio de comunicação com os signos que fazem parte dos elementos sociais. Isso significa que ao interpretarmos os signos, criamos, também, um caminho para a formação de conceitos que definem determinados fatos e fenômenos que estão presentes na sociedade. Em suma, podemos dizer o uso da linguagem permite construir novas relações com os conceitos que são representados, a partir de figuras sígnicas (KOZEL, 2004 e 2005).

Essa relação entre a linguagem e a expressão do conceito tem fundamental importância na prática pedagógica, já que os conteúdos escolares são desenvolvidos pelos conceitos que definem e especificam uma determinada disciplina escolar, como é o caso da Geografia. Couto (2006), nos colabora com o seguinte apontamento:

A palavra, desde o início, constituiu-se em um tipo primário de conceito, na medida e que reproduz uma generalização da realidade, atitude fundamental à formação de conceitos. No entanto, quando se utiliza uma palavra, o desenvolvimento dela no pensamento da criança ainda percorrerá longo percurso: no início a palavra se refere aos objetos da experiência concreta e depois sem perder esse lastro de concretude, ela permite ao pensamento emancipar-se do concreto e da percepção; na verdade a palavra torna-se uma síntese mais ampla e complexa do concreto com o abstrato, transformando-se, assim, num símbolo do conceito. (COUTO, 2006, p. 88)

O acúmulo das atividades desenvolvidas no trabalho didático-pedagógico de Geografia pressupõe a formação de uma leitura considerada científica, que vem a ser a análise espacial, bem destaca em parágrafos anteriores. Podemos dizer, ainda, que esta análise refere-se ao raciocínio geográfico, ou seja, à capacidade cognitiva e intelectual de interpretar os mais diferentes lugares tendo como questionamento central o topos.

Numa análise mais próxima das questões escolares, Callai (1995) nos colabora ao indicar que a necessidade de desenvolvermos um trabalho baseado no estudo do conceito permite que seja superada a idéia simplista e naturalizada da formação do espaço geográfico.

A grande questão é conseguir dar unidade ao estudo que é feito, buscando compreender-se a ação do homem no processo de construção do espaço. E este não pode ser o espaço abstrato nem amplo, mas deve ser o espaço concreto da vida do homem. O espaço geográfico é um espaço que não é dado naturalmente como um palco onde acontecem os fenômenos. É um espaço que contém características e a ação do homem. Quer dizer, o espaço supõe todos os dados naturais (ao natural ou transformados), os dados humanos, sociais (as relações que acontecem entre os homens, expressas, muitas vezes, de formas diferenciadas) e o resultado destas relações, o produto, materializado no espaço. É um espaço prenhe de relações, carregado de história, que tem uma circunscrição de limites. Ao ser expresso por uma paisagem, é a visualização concreta das relações sociais e da sociedade com a natureza, o qual 
denominamos espaço geográfico. (p. 38)

Esses pontos confirmam a necessidade de iniciarmos nas práticas escolares da Educação Básica o estudo sobre os conceitos, que contribuem tanto para explicar a própria Geografia como os diferentes contextos que interferem na produção do espaço. Nesse sentido, a análise sobre o espaço geográfico torna-se uma ação presente no processo de ensino dessa disciplina escolar.

Entretanto, nos cabe uma indagação: como devemos introduzir o estudo dos conceitos espaciais nas atividades didático-pedagógicas de Geografia? Um caminho para resolvermos essa situação é o uso de linguagens específicas para apresentar aos alunos como os conceitos estão presentes nas práticas cotidianas. Sendo assim, se um dos principais conceitos da Geografia é o espaço (geográfico), nada melhor do que utilizarmos uma linguagem que o represente de maneira mais ampla e clara, neste caso referimo-nos ao mapa. Esse produto cartográfico tem as características específicas para organizar em sua representação os elementos que estruturam e constituem o próprio espaço, além de nos fornecer uma leitura mais coadunada com as análises geográficas.

Ao reconhecermos a necessidade de trabalhar no ensino de Geografia com a formação de conceitos, a partir do uso e da construção de linguagens específicas como o mapa, é fundamental conhecermos que tipo de conhecimento geográfico almeja-se formar nos alunos da Educação Básica. Já que no final desta etapa o resultado estará presente nas práticas cotidianas de leitura e de análise da realidade, por parte desses jovens.

Assim, os ideais apresentados até aqui poderiam se tornar somente uma inspiração teórica se não forem construídas metodologias capazes de colaborar com o trabalho docente e que apontem caminhos para solucionar estes problemas que ocorrem na prática didática de Geografia. Desse modo, a categoria espacial "lugar" é destacada para contribuir, significativamente, no objetivo de alcançar as transformações desejadas.

A valorização que queremos dar ao lugar_está relacionado ao fato de que ao compreendermos determinados espaços - como a cidade, por exemplo - o aluno terá possibilidade de ampliar suas leituras a respeito dos fenômenos que interferem no processo de produção e transformação do seu cotidiano, bem como produzir representações espaciais que expressem as análises espaciais. Para isso é importante que a escola desenvolva atividades que permitam a reflexão do aluno sobre seu espaço de vivência, para que o mesmo não entenda a cidade somente pelos principais eixos viários ou pelas áreas de lazer. A cidade deve ser analisada com um todo (em suas relações internas e externas), para que o estudante possa compreendê-la nas suas diferenças, desigualdades, exclusões/ inclusões e nos seus espaços segregados. Ao seguirmos essas indicações temos condições de superar a idéia de espaço vazio, muito presente na leitura e na construção do mapa mental das cidades, como nos explica Bauman (2001):

Numa de minhas viagens de conferências (a uma cidade populosa, grande e viva do sul da Europa), fui recebido no aeroporto por uma jovem professora, filha de um casal de profissionais ricos e de alta sociedade. Ela se desculpou porque a ida para o hotel não seria fácil, e tomaria muito tempo, pois não havia como evitar as movimentadas avenidas para o centro da cidade, constantemente engarrafadas pelo tráfego pesado. De fato, levamos quase duas horas para chegar ao lugar. Minha guia ofereceu-se para conduzir-me ao aeroporto no dia da partida. Sabendo quão cansativo era dirigir na cidade, agradeci sua gentileza e boa vontade, mas disse que tomaria um táxi. O que fiz. Desta vez, a ida ao aeroporto tomou menos de dez minutos. Mas o motorista foi por fileiras de barracos pobres, decadentes e esquecidos, cheios de pessoas rudes e evidentemente desocupadas e crianças sujas vestindo farrapos. A ênfase de minha guia em que não havia como evitar o tráfego do centro da cidade não era mentira. Era sincera e adequada a seu mapa mental da cidade em que tinha nascido e onde sempre vivera. Esse mapa não registrava as ruas dos feios "distritos perigosos" pelas quais o táxi me levou. No mapa mental de minha guia, no lugar em que essas ruas deveriam ter sido projetadas havia, pura e simplesmente, um espaço vazio. (BAUMAN, 2001, p. 121)

Mercator - volume 9, número 20, 2010: set./dez. 
São considerações como essas que nos contribuem para reforçar a concepção de que para entendermos os espaços de vivência precisamos utilizar recursos que permitam repensar a produção dos lugares. Para isso, o uso de mapas mentais articulado ao ensino de Geografia possibilita ao aluno a transposição, para essa linguagem cartográfica, de suas análises espaciais e, ao mesmo tempo, ampliar seu conhecimento. Assim, no momento em que o aluno construir, em sala de aula, o mapa de sua cidade, tendo a colaboração dos saberes científicos ensinados na escola, esse indivíduo fará uma revisão do espaço representado e poderá incorporar leituras individuais, coletivas e, quiçá, questionadoras.

Contudo, tão importante quanto entendermos a cidade, é criarmos condições para que os alunos produzam instrumentos que contribuam no seu raciocínio geográfico. Desta forma, o mapa mental torna-se um bom exemplo.

\section{MAPAS MENTAIS NO ENSINO DE GEOGRAFIA: uma integração necessária}

As atividades relacionadas com a Cartografia encontram-se, nos dias de hoje, muito próximas das práticas escolares. É difícil encontrarmos um aluno que não tenha participado, enquanto estudante da Educação Básica, de atividades escolares tendo o mapa como um recurso didático. Nos últimos 30 anos, a representação espacial obteve uma significativa inclusão nas propostas pedagógicas, principalmente no que se refere a disciplina de Geografia. Esse contexto nos permite esboçar a seguinte idéia, de que atualmente o uso e a construção do mapa estão muito próximos do processo de ensino-aprendizagem de Geografia, pelo menos no campo teórico-metodológico. Podemos confirmar a presente afirmação com base nos estudos de Oliveira (1978), Paganelli (1982), Simielli (1986), Almeida (1994) e Passini (1996), que são consideradas pesquisas pioneiras nessa temática e que tinham um objetivo comum, que era de consolidar uma valorização sobre a representação cartográfica nas práticas escolares de Geografia.

Entretanto, mesmo reconhecendo que houve um sensível avanço na relação do mapa com o ensino de Geografia, ainda podemos encontrar determinadas situações que denotam a construção desta relação apenas no plano do discurso. Ou, em outros casos, deparamos com uma prática da Cartografia mais atrelada aos contextos tradicionais desta ciência, em que a base cartesiana torna-se a única possibilidade de referencial teórico-metodológico.

A partir desses apontamentos, temos condições de verificar que essa preocupação em avançar no trabalho com o mapa não é uma luta individual. Além dos pesquisadores que desenvolveram dissertações e teses, inúmeros outros professores compartilham da necessidade de integrar o mapa no ensino de Geografia para além de uma Cartografia tradicional. Um dos percursores desta temática foi Harley (1991), que provoca aos leitores de seus textos novas indagações, principalmente relacionadas as estruturas rígidas que constituíram a própria Cartografia,, e que por escolhas ideológicas, negligenciaram determinados conhecimentos e formas de representação espacial. Para o referido autor, esse fato resultou num retrocesso no desenvolvimento da Cartografia ao longo dos anos, por atribuir uma categoria de valor para considerar o que era um "verdadeiro" mapa e o que deveria ser descartado.

Nesse sentido, para que as idéias fossem validadas, era necessário realizar um estudo analítico sobre os fatores que determinavam ou condicionavam determinados fatos e contextos. A racionalidade científica, que perdurou durante muitos séculos (e que, em alguns casos, perdura até hoje), negligenciou a possibilidade de se fazer ciência com base em outras leituras ou propostas. Como resultado, a compreensão que se tem atualmente do mundo e de suas interrelações são, praticamente, todas baseadas na ordem lógico-matemática (GIRARDI, 1997 e KOZEL, 2005).

Questões como essas são destacadas por Harley (1991) e Girardi (1997), que identificam que nem todos os mapas eram considerados válidos para expressar as novas formas da organização da sociedade. 
Os mapas eram considerados marcos significativos da evolução da humanidade; por conseguinte, aqueles que não indicassem algum progresso ruma à objetividade deixavam de ser seriamente estudados. Mesmo alguns dos primeiros mapas produzidos pela cultura européia, como os grandes planisférios da Idade Média Cristã, eram considerados indignos de atenção científica. No início deste século, Charles Raymond descreveu os principais mapas da baixa Idade Média - o Hereford e o Ebstorf - como "mostruosidades não-científicas, absolutamente inúteis". (HARLEY, 1991, p. 05)

Durante muito tempo se fez uma história da cartografia que separava os mapas "primitivos" e "antigos" dos "contemporâneos" (leia-se ocidentais, científicos e portanto "verdadeiros"). Nesta classificação está claro o preconceito em relação aos mapas tanto das sociedades tecnologicamente não-avançadas e mesmo quanto aos mapas "não-científicos". Convencionou-se chamar de mapa aquelas construções que obedecem padrões. No decorrer da formação em geografia somos treinados a operacionalizar e a construir tais mapas; eventualmente a analisá-los. Ainda assim é comum balizar esta análise dentro de especificações técnicas da própria cartografia. Julgamos se o mapa é bom ou não, se é correto ou não a partir da existência ou não de escala, de orientação, de título, de uso de variáveis visuais pertinentes, de coerência legenda-conteúdo, entre outros elementos. (GIRARDI, 1997, p. 16)

Na tentativa de reescrever a História da Cartografia, Harley (1991) destaca que os mapas antigos, que remontam a própria História da humanidade, vieram antes do desenvolvimento das escrituras e da notação matemática em muitas sociedades. Isso revela a importância que a representação espacial possui no entendimento da formação social dos indivíduos. O autor faz, também, um alerta ao analisar com mais cuidado o desenvolvimento da Cartografia, já que os mapas produzidos na pré-história tornaram-se somente reconhecidos e aceitáveis aos estudos dessa ciência há poucos anos. Antes, a rigidez e, principalmente, a ocidentalização da Cartografia (SANTOS, 2002) não permitia adotar outros tipos de produções cartográficas provindas de sociedades, consideradas, primitivas (HARLEY, 1991, 2009). Ou, como nos esclarece Santos (2002, p. 25-26),

Do ponto de vista cartográfico, o que pode nos servir de referência fundamental é que todo os mapas conhecidos, em todos os momentos da história, representam, de uma maneira ou de outra, a leitura de mundo da sociedade que os constitui (e, ainda, constrói) e são, portanto, potencialmente capazes de nos oferecer elementos de leitura da cosmologia subjacente a seus atores. Vale lembrar que os mapas possuem, genericamente, uma aparência meramente descritiva - quase invocando para si um certo caráter de neutralidade, tão caro a certas tradições positivistas -, o que nos obrigará a um esforço contínuo de comparação e identificação (releituras, portanto), sem o qual tenderemos a permanecer na superficialidade - um certo "congelamento" do fenômeno - que a linguagem cartográfica geralmente nos indica.

O contexto que justifica o fato das sociedades européias negarem os demais produtos cartográficos originados de outras culturas (leia-se, diferentes perspectivas da realidade e da representação dos espaços conhecidos), era atribuído pela necessidade dos europeus observarem a sua própria imagem. Esta situação reforçava os elementos culturais, políticos, econômicos e sociais produzidos pelas nações desse continente, e assim transformavam a representação espacial em veículo de afirmação e padronização sobre outros grupos sociais. Em contrapartida, a ciência produzida nesta época tratou logo de fundamentar as justificativas que se dava a esta negação, alicerçada no fato de que os mapas não-ocidentais ou não-europeus jamais atendiam às bases de orientação, das escalas regulares, dos elementos de geometria euclidiana, entre outros. Assim, os mapas eram produzidos com outros referenciais de balizamento espacial e que, portanto, não seria necessário estudar esses diferentes códigos de representação. (BLACK, 2005)

Podemos incluir outros elementos que a Cartografia "eurocêntrica" desconsiderou como sendo representações espaciais válidas, por exemplo a presença de contextos míticos, psicológicos e sim- 
bólicos ou que tivessem um uso prático para uma determinada sociedade, e que não atendessem os modelos científicos desenvolvidos pela Cartografia européia. Desse modo, os mapas foram restritos há tipos específicos de produção e de espaços.

Contrariando as posições limitadas a respeito do mapa, Harley (1991) destaca que ao considerar diversos produtos cartográficos como objetos da representação espacial, a própria Cartografia amplia seus horizontes na compreensão da História da humanidade e torna mais visível períodos que antes eram desconsiderados na produção de mapas. Por outro lado, o autor indica que nos dias de hoje, temos possibilidade de observar que inúmeros mapas produzidos pelos europeus, após a ocupação da América, obtiveram suas bases cartográficas provindas dos mapas e dos conhecimentos geográficos dos povos indígenas, que foram suprimidos, principalmente, pelas monarquias da península ibérica. Se ocorreu uma valorização sobre os diferentes tipos de mapas encontrados no contato com outras sociedades, essa inclusão era realizada apropriando-se desses novos saberes como um conhecimento europeu.

As considerações feitas acerca da História da produção dos mapas evidenciam a necessidade de ampliarmos as possibilidades na sua construção e de não restringirmos a sua valorização a determinados mapas que atendam somente uma estrutura rígida e, muitas vezes, limitada sobre o espaço. Dentre todos os apontamentos de Harley (1991), a última frase que este autor apresenta em seu artigo é um ponto de reflexão:

Os mapas sempre foram imagens mentais. Hoje continuamos a considerá-los uma forma de ver, mas começamos a entender o significado de "ver". Em vez de pensarmos que os mapas são um espelho do mundo, passamos a vê-los como um simulacro: algumas vezes, mais importante que o território representado; freqüentemente, uma redescrição do mundo em toda a sua diversidade cultural. (HARLEY, 1991, p. 09)

São questões como essas que contribuíram para os estudos de Kozel (2004). Para a presente autora, é fundamental reconhecermos a influência histórica que a Geografia recebeu das estruturas racionalistas para o entendimento dos fenômenos que ocorriam no espaço. Ao termos ciência dessa posição do pensamento geográfico, torna-se mais evidente compreendermos a relação entre a formação da própria Geografia e o destaque a Cartografia mais tradicional. Ela aponta:

Na geografia, Humboldt defendia a idéia de que as condições naturais, como clima e temperatura, interferiam no comportamento e na capacidade de progresso dos seres humanos, caracterizando o determinismo ambiental. E, Ratzel, numa clara alusão ao darwinismo, enfatizava que o desenvolvimento dos povos se determinava pelo nível de adaptação ao ambiente em que viviam. Entretanto, se o estudo do meio era o cerne da pesquisa geográfica, estava sujeito a alterações, proporcionadas pela ação humana, o que passa a ser revisto por La Blache quando afirma que o ser humano ao se adaptar transforma a natureza de acordo com suas necessidades, principalmente pela sobrevivência. Entretanto, o princípio geográfico se restringia à descrição da Terra e a proceder a um inventário das ações humanas desenvolvidas. (KOZEL, 2004, p. 165)

Mais do que limitar a possibilidade de formar novas interpretações, essas posturas rígidas foram responsáveis por estabelecer um olhar menos flexível sobre os encaminhamentos da própria ciência. Consequentemente, foi possível construir a falsa idéia de que os mapas seriam portadores de uma neutralidade ao representar os espaços. Esse tipo leitura forjou uma análise sobre a Cartografia que menosprezou as diversas possibilidades e inúmeras qualidades que essa representação espacial poderia contribuir para o entendimento da sociedade. Para Girardi (1997), essa situação permitiu que a Cartografia fosse compreendida somente como o resultado de uma atividade técnica ou mecânica, portanto sem a inclusão das interfaces críticas, reflexivas e subjetivas. Como proposta de superar esses limites destacados pelos autores supracitados, as considerações de Board (1984, 
apud GIRARDI, 1997) merecem ser enfatizadas:

[...] é no campo da educação geográfica que devemos olhar com maior interesse a pesquisa do uso geográfico do mapa. [...]. É vital colocar mais esforços na melhoria da qualidade da leitura do mapa, não apenas perpetuar gerações de compradores de mapas, mais desenvolver habilidade úteis para cidadãos de um mundo incrivelmente complexo e desconcertante. (BOARD, 1984 apud GIRARDI, 1997, p. 16)

Se o mapa esteve dividido entre a proposta mais cartesiana e matemática, no viés da Geografia pragmática, e numa interpretação de instrumento de manipulação e dominação, pela Geografia Crítica (movimento de renovação) (TEIXEIRA, 2001), será que o caminho mais indicado não é de superarmos estas duas visões "reducionistas" de análise do mapa? Neste sentido, entendemos que uma proposta para atender essa questão pode ser a da construção do mapa em outra vertente, que nesse caso destacamos o mapa mental. Entretanto, consideramos necessário esclarecer que essa proposta não exclui as demais produções cartográficas.

Na mesma perspectiva de ampliarmos e, principalmente, de superarmos as possibilidades de uso da Cartografia, Katuta (2005) nos apresenta a sua concepção sobre o mapa, que contribui para reforçar a idéia de que a produção cartográfica deve servir para além das bases matemáticas, pois estas restringem muito a Cartografia a uma visão positivista do espaço, eurocêntrica e, muitas vezes, voltada para a exploração do espaço - pelo capital. Em outro artigo, Katuta (2007) enfatiza a relevância da integração da representação espacial nas práticas pedagógicas do ensino de Geografia. A primeira preocupação está em estabelecer que no processo de formação escolar os estudantes tenham contato tanto com as linguagens já prontas, confeccionadas como produtos culturais, como com o processo de construção destas linguagens, para que se tenha possibilidade de desenvolver diferentes leituras da realidade e, ao mesmo tempo, reconhecer que este processo é dialético. $\mathrm{O}$ uso das diferentes linguagens deve ter um objetivo na efetivação das práticas pedagógicas que supere a idéia de somente "enfeitar" a prática da sala de aula. As linguagens precisam fazer parte da formação dos saberes escolares.

Uma das qualidades dessa mudança, mencionada por Katuta (2007), está na possibilidade de alterar os elementos que validam a produção do saber. Em outras palavras, significa dizer que o conhecimento não deve ser analisado somente como um resultado do ato exclusivamente científico. Pelo contrário, é fundamental que sejam integrados os aspectos subjetivos e perceptivos de cada indivíduo na produção das linguagens. Por fim, a dialética entre esses dois processos é que contribui para o desenvolvimento do saber.

As atuais mudanças projetam a construção de um ensino de Geografia mais próximo de questões latentes da atualidade, como a compreensão de problemas urbanos que afetam a sua própria cidade, da integração do espaço local com o processo de globalização - suas vantagens e desvantagens -, e o entendimento sobre os fatores que interferem na transformação dos espaços. Isto não significa que devemos descartar ou negligenciar as propostas consideradas mais tradicionais. $\mathrm{O}$ que queremos salientar é a necessidade de incluir, cada vez mais, novos recursos e, principalmente, novas linguagens que nos permitam ampliar o conhecimento geográfico para além das "quatro paredes" da sala de aula. $O$ aluno precisa estabelecer relações entre os saberes aprendidos na escola com a prática da vida cotidiana.

Para alcançarmos esses ideais, consideramos imprescindível a inclusão da participação (ativa) dos mapas. Assim, muito mais importante do que apenas localizarmos um determinado fenômeno numa representação cartográfica, é fundamental que possamos desenvolver atividades, leituras e interpretações (raciocínios) que permitam com que o aluno entenda a produção de um dado contexto no espaço. Nesse sentido, ao possibilitarmos que o aluno desenvolva esse tipo de raciocínio, que interpretamos como raciocínio geográfico, devemos salientar que essa prática seja um objetivo comum e pertinente a todos os programas curriculares da Educação Básica.

Ao concordarmos com esses pontos, a respeito da necessidade de superarmos a perspectiva

Mercator - volume 9, número 20, 2010: set./dez. 
mais rígida da produção do mapa, o encaminhamento que se dá refere-se a integração da Cartografia com a compreensão do processo de produção do espaço, que se estabelece no fato de que é o próprio homem o responsável pela construção e transformação do meio espacial. Com base nas premissas acima, precisamos buscar na produção dos mapas propostas que retratem e representem, de maneira mais ampla, os inúmeros elementos e contextos que participam da sociedade.

Teixeira (2001), nos apresenta uma preocupação sobre como cada indivíduo compreende o seu espaço. Já que o espaço é produto das relações sociais que interferem no desenvolvimento humano. Diante deste questionamento, torna-se válido investigar sobre a representação do espaço, a partir de cada sujeito integrante da sociedade. Assim, nos estudos do espaço vivido, além de ampliarmos o conhecimento do mundo produzido pelos próprios indivíduos, como resultado histórico-social, é necessário, também, compreendermos a leitura que seus habitantes fazem sobre este espaço. Portanto, reconhecemos o quão importante é a existência de inúmeras interpretações do mundo, provindas do plano das experiências, das vivências, mas sempre fundamentadas nas leituras científicas.

Os mapas mentais dão possibilidade do seu autor incluir elementos subjetivos que, na maioria das vezes, não estão presentes nos mapas tradicionais. Essa característica torna mais rica esta representação de próprio punho, por incluir contextos que podem ampliar a compreensão do espaço. Desse modo, concordamos com Kozel (2007) quando explica que:

As representações provenientes das imagens mentais não existem dissociadas do processo de leitura que se faz do mundo. E nesse aspecto os mapas mentais são considerados uma representação do mundo real visto através do olhar particular de um ser humano, passando pelo aporte cognitivo, pela visão de mundo e intencionalidades. Essa multiplicidade de sentidos que um mesmo "lugar" contém para seus moradores e visitantes está ligada, sobretudo ao que se denomina de imaginação criadora, função cognitiva que ressalta a fabulação como vetor a partir do qual todo ser humano conhece o mundo que habita. O espaço percebido pela imaginação não pode ser o espaço indiferente, é um espaço vivido. E vivido não em sua positividade, mas com todas as parcialidades da imaginação. (p. 121)

Dessa maneira, o mapa deve incluir no seu trabalho de representação, características e elementos que anteriormente eram consideradas desnecessárias ou sem valor científico, pois estas não estavam dentro dos padrões científicos que determinavam a construção cartográfica cartesiana. A necessidade de valorizarmos esse tipo de representação do mapa, mais flexível e mais integrado ao processo de mudanças que ocorrem na sociedade, se justifica pelo fato de que esta concepção nos permite formar indivíduos capazes de compreender o mapa para além do processo de cópia. A idéia é tornarmos o mapa num meio de linguagem que contribua na expressão e interpretação do cotidiano.

Girardi (1997), nos apresenta um estudo entre o mapa e a escrita, fundamentado nas pesquisas de Robinson \& Petchenik (1976, apud GIRARDI, 1997), no qual explica que o processo de leitura do mapa é resultado de uma não-linearidade no ato de leitura e compreensão, já que a representação cartográfica possibilita uma visão do conjunto. Assim, o leitor possui autonomia para seguir um ou diversos caminhos. Podemos avançar nessa análise ao integrar a concepção do mapa mental, principalmente se o mapa está alicerçado num processo de leitura não-linear, da mesma maneira devemos pensar nos seus métodos de construção. Portanto, consideramos de suma importância reconhecer que existem diversas formas de produzir um mapa, já que a leitura da própria realidade pode ser múltipla.

Paralelamente, essas considerações devem ser integradas com o fato de que a própria cognição humana não se encontra vinculada a um único modelo de representação. São inúmeros os desdobramentos que o saber humano pode desenvolver e isto deve ser considerado ao compreender o mapa. O contrário disto, quer dizer, a afirmação de que deve existir somente um padrão para a construção cartográfica ou no processo intelectual dos indivíduos, gera um preocupante fator que se estabelece no empobrecimento do desenvolvimento cultural e na possibilidade de limitar a liberdade do pensamento. 
Sobre essas questões, outro texto de Girardi (2005) nos sinaliza a necessidade de reconhecermos a presença da ideologia no processo de construção do mapa e da importância de expandirmos as formas de produção da Cartografia, superando a idéia de hierarquia ou padronização da linguagem cartográfica.

E os mapas das nações indígenas e de outras sociedades cujo referencial é outro? Não são mapas? E mapas turísticos, de propaganda imobiliária, de jornal... A crítica corporativa resolveu essa questão mudando o nome dessas representações: croquis, mapa mental, mapa ilustrativo... Essa visão eurocêntrica e elitista da cartografia em muito pouco contribuía para fazer avançar a discussão sobre o mapa na Geografia. É preciso lembrar que nesse período o paradigma neopositivo na Cartografia ganhava muita força devido ao crescimento da informatização, refletida na Cartografia Digital e nos Sistemas de Informações Geográficas. (GIRARDI, 2005, p. 65)

Outra autora que nos colabora no debate sobre a necessidade de superarmos o modelo linear é Massey (2008), que mesmo não tendo abordado diretamente sobre as questões relativas ao mapa, destaca quão prejudicial é para os indivíduos e para a própria ciência a imposição de uma única visão ou concepção de mundo. Massey nos ilustra esse fato pela valorização do conceito de tempo na formação das sociedades, a partir da influência européia e capitalista sobre o conceito de espaço. Essa estrutura foi responsável por constituir nas relações sociais desses territórios influenciados um elogio a dimensão temporal, que se configura materialmente na comparação de diversos grupos humanos do globo num único tempo. Situação esta que nega o reconhecimento das diferenças espaciais que identificam, marcam, diferenciam e valorizam determinadas sociedades. Em síntese, esse processo representa, também, um retrocesso para o desenvolvimento humano, ainda mais quando observamos na atualidade os padrões culturais que estão em evidência e que norteiam diversas nações.

As considerações das duas autoras (GIRARDI, 2005 e MASSEY, 2008), indicam a importância de desenvolvermos análises científicas de maneira mais ampla e diversificada. Situação que pode ser muito bem articuladas ao tratamento e interpretação das produções cartográficas, que almeja incluir outras perspectivas espaciais no processo de construção dos mapas. Inserido nessa estrutura é que se apresenta o mapa mental. Muito mais do que criarmos uma nova divisão na Cartografia, este tipo de representação espacial se instaura na possibilidade de fazer com que o mapa possa expressar diferentes elementos presentes no cotidiano da sociedade, e que seus próprios construtores tenham a liberdade de incluir na sua produção interpretações particulares e/ou coletivas.

A busca por estabelecermos novos vínculos da Cartografia com as práticas pedagógicas de Geografia pode ser expressa nas preocupações de Pinheiro (2005), ao tratar sobre a influência dos mapas de perspectiva matemática, geométrica e na formação da compreensão espacial. Este autor nos diz que, geralmente, não se dá a possibilidade ao aluno de desenvolver uma capacidade de representar e de ler o espaço sob diferentes formas de representação. O fato pode ser compreendido, a partir dos seguintes contextos:

Representações mentais do mundo são similares aos mapas cartográficas correspondentes, mas há uma distinção muito importante. As projeções cartográficas são expressas através de fórmulas matemáticas, ao passo que não existe linguagem equivalente para traduzir os "mapas mentais". A partir de qualquer projeção cartográfica existe a possibilidade de reconstruír os tamanhos reais, formas e posições de nosso planeta quase-esférico, mas no caso dos mapas cognitivos "a mente humana parece reorganizar completamente as informações" (Tversky, 1992, p. 208). Tais distorções não significam erro, no sentido das ciências físicas ou das engenharias, mas uma reorganização funcionalmente orientada da informação (McDonald \& Pellegrino, 1993; Tversky, 1992). Ao mesmo tempo, no nível social, essas distorções tornam o processo de comunicação mais simples e fácil, pois "é justamente essa estruturação cognitiva do ambiente que nos capacita a organizar nosso mundo de um modo reconhecível e administrável" (Ittelson [et al], 1974, p. 14). (PINHEIRO, 2005, p. 164).

Mercator - volume 9, número 20, 2010: set./dez. 
A citação acima vai ao encontro do que Seemann (2003) já havia expressado sobre a necessidade de avançar na compreensão da Cartografia. Ele destaca que o mapa apresenta duas possibilidades de mapeamento: o funcional e o planimétrico. Sendo funcional, o mapa que busca representar a relação dos homens com os diferentes espaços, e o planimétrico, as regras cartesianas estabelecidas para padronizar as produções cartográficas. No primeiro caso, a relação não está fundamentada no tamanho, distâncias ou dimensões reais de um determinado espaço, mas com as dimensões construídas subjetivamente pela sociedade em relação ao uso dos espaços ou facilidades de locomoção no espaço. A subjetividade humana tem muita influência nesse tipo de mapeamento (o funcional). É interessante, ainda, completarmos esta análise com o seguinte alerta:

Pensar a Cartografia de uma maneira menos dogmática (e, quem sabe, menos cartográfica e mais cartográfica) exige mais consciência, criatividade, ousadia, coragem e, sobretudo, uma postura mais humana ou até humanística [...] (SEEMANN, 2003, p. 58).

São esses aportes teórico-metodológicos que nos ajudam a fundamentar a nossa valorização para esse tipo de representação cartográfica. Os mapas mentais podem colaborar, significativamente, com a prática docente ao identificar os limites e avanços que os alunos apresentam em determinados conteúdos (ZDI, VIGOTSKI, 2000), como também no processo de ensino-aprendizagem deste estudante, ao ter a possibilidade de representar os conhecimentos geográficos numa linguagem mais aberta, que destaque seus produtos como objetos de expressão do espaço.

\section{CONSIDERAÇÕES FINAIS}

Ao termos clareza de que o ensino de Geografia está intimamente ligado ao estudo do espaço (geográfico) e de que a presença da linguagem cartográfica se dá para além das estruturas cartesianas mais rígidas, o resultado desse processo na formação escolar dos estudantes permitirá que seja consolidada uma análise espacial sobre o cotidiano de maneira mais ampla e crítica.

Para que essas práticas sejam consolidadas, torna-se fundamental destacar a contribuição e participação do ensino dos conceitos no processo de ensino-aprendizagem de Geografia. O conceito, conforme apontamentos de Couto (2006) e Vigotski (2000), será o eixo central para o desenvolvimento de um saber mais científico na formação dos alunos, fato que poderá ser materializado na construção de uma leitura mais atenta as modificações e/ou permanências que ocorrem no espaço.

Ao darmos seguimento nessas ações temos a possibilidade de construirmos um trabalho com o mapa para além da proposta de um fim em si mesmo, já que a inserção da Cartografia nas práticas escolares, como foi destacado ao longo desse texto, busca promover uma colaboração para a formação de uma leitura/interpretação/raciocínio geográfico. Ou seja, o mapa como um meio e não como um fim para as aulas de Geografia. Isso fortalece a participação da linguagem cartográfica nas propostas didáticas desenvolvidas em sala de aula, superando a concepção de ilustração ou de atividade lúdica, sem relação com o próprio conhecimento da Geografia. Essa perspectiva é muito destaca por Katuta (2007, p. 231), ao dizer:

É na lida cotidiana docente com as diferentes linguagens que os desafios inerentes à sua (re)apropiação e repensar comparecerão. Daí a necessidade de o professor ter uma postura investigativa com relação à própria prática pedagógica, caso contrário, suas ações em sala de aula correm o sério risco de se tornarem difusas ou empobrecidas na medida em que acabam por se encerrarem em si. Isto pode ocorrer quando o uso das linguagens se realiza de maneira aleatória, apenas para tornar a aula menos maçante ou cansativa. Pereira (1999, p. 118) define o educador investigador da seguinte maneira: “[...] um profissional dotado de uma postura interrogativa e que se revele um pesquisador de sua própria ação docente." 
Dessa forma, o que queremos salientar é a significativa importância de promover no ensino de Geografia um estudo mais voltado a produção e transformação do espaço, a partir dos conteúdos específicos ou conceitos que são trabalhados ao longo do ano letivo, permitindo que o aluno tenha condições de compreender a sociedade com base na perspectiva espacial.

Por isso, do mesmo modo que Harley (1991), Girardi (2005) e Katuta (2007) defendem a valorização do uso de diferentes formas de representação na formação escolar dos indivíduos, o mapa mental se caracteriza por permitir que os alunos expressem suas múltiplas interpretações, questões, dúvidas ou análises que não estão presentes, muitas vezes, nos mapas padronizados - previamente construídos, presentes em livros didáticos ou Atlas escolares.

Assim, a integração dos mapas mentais poderá ajudar no processo de ensino-aprendizagem dessa disciplina por desenvolver nos alunos uma leitura sobre a realidade mais atenta as dinâmicas espaciais que interferem na organização da sociedade. Portando, a proximidade da representação espacial com o ensino dos conteúdos e conceitos deve se fazer presente ao longo do currículo escolar de Geografia. Muito mais do que atender as normativas pedagógicas das escolas ou dos documentos oficiais que orientam os trabalhos didáticos, essa prática permitirá a formação de um indivíduo mais consciente da análise espacial presente na construção da nossa vivência.

\section{REFERÊNCIA BIBLIOGRÁFICA}

ALMEIDA, Rosângela Doin de. Proposta metodológica para compreensão de mapas geográficos. Tese de Doutorado. Universidade de São Paulo, São Paulo, 1994.

BAUMAN, Zygmunt. Modernidade líquida. Rio de Janeiro: Jorge Zahar Editor, 2001.

BLACK, Jeremy. Mapas e história: construindo imagens do passado. Bauru: EDUSC, 2005.

CAVALCANTI, Lana de Souza. Geografia, escola e construção de conhecimentos. Campinas: Papirus, 1998.

CALLAI, Helena Copetti. Geografia: um certo espaço, uma certa aprendizagem. Tese de Doutorado. Universidade de São Paulo, São Paulo, 1995.

CALLAI, Helena Copetti. Estudar o lugar para compreender o mundo. In: CASTROGIOVANNI, Antônio (org.). Ensino de Geografia: práticas e textualizações no cotidiano. Porto Alegre: Mediação, 2000. p. 83-134.

CALLAI, Helena Copetti. Aprendendo a ler o mundo: a geografia nos anos iniciais do ensino fundamental. Cadernos do Cedes. Centro de Estudos Educação Sociedade. Vol. 25, n. 66. (maio/ago 2005) São Paulo: Cortez, 2005. p. 227-247.

CLAVAL, Paul. A revolução pós-funcionalista e as concepções atuais da Geografia. In: MENDONÇA, F. \& KOZEL, S. (orgs.). Elementos de epistemologia da geografia contemporânea. Curitiba: Ed. da UFPR, 2002. p. 11-43.

COUTO, Marcos Antônio Campos. Pensar por conceitos geográficos. In: CASTELLAR, Sônia (org.). Educação geográfica: teorias e práticas. 2. ed. São Paulo: Contexto, 2006. p. 79-96.

GIRARDI, Gisele. A cartografia e os mitos: ensaios de leitura de mapas. Dissertação de Mestrado. Universidade de São Paulo, São Paulo, 1997.

GIRARDI, Gisele. Aventuras da leitura de mapas. In: SEEMANN, Jörn (org.). A aventura cartográfica: perspectivas, pesquisas e reflexões sobre a cartografia humana. Fortaleza: Expressão Gráfica e Editora, 2005. p. 61-72.

GOMES, Maria do Carmo Andrade. Velhos mapas, novas leituras: revisitando a história da Cartografia. In: Revista GEOUSP - Espaço e Tempo, nº 16. USP: São Paulo, 2004. p. 67-79.

HARLEY, J. Brian. A nova história da cartografia. In: O Correio da Unesco, v. 19, n. 8. Ago de 1991. p. 4-9. HARLEY, J. Brian. Mapas, saber e poder. Confins: Revista Franco-brasileira de Geografia, n. 5. (jan./jun. 2009). Disponível $<\mathrm{http}: / /$ confins.revues.org/index34html>. Acesso em 24 de agosto de 2009.

KAECHER, Nestro André. A geografia crítica - alguns obstáculos e questões a enfrentar no ensino-aprendizagem de geografia. Boletim Gaúcho de Geografia. Vol. 01, nº 01, Jan/Jun. Porto Alegre: AGB-PA, 2002. p. $45-65$.

Mercator - volume 9, número 20, 2010: set./dez. 
KAECHER, Nestro André. A Geografia escola na prática docente: a utopia e os obstáculos epistemológicos da Geografia Crítica. Tese de Doutorado. Universidade de São Paulo, São Paulo, 2004.

KATUTA, Ângela Massumi. A(s) natureza(s) da Cartografia. In: SEEMANN, Jörn (org.). A aventura cartográfica: perspectivas, pesquisas e reflexões sobre a cartografia humana. Fortaleza: Expressão Gráfica e Editora, 2005. p. 39-59.

KATUTA, Ângela Massumi. A educação docente: (re)pensando as suas práticas e linguagens. REVISTA TERRA LIVRE. Ano 23, v. 1, n. 28. Jan-Jun/2007. Presidente Prudente: AGB, 2007. p. 221-238.

KOZEL, Salete. Das "velhas certezas" as (re)significação do geográfico. In: SILVA, A. A. D. da \& GALEANO, A. (orgs.). Geografia: ciência do complexus: ensaios transdiciplinares. Porto Alegre: Sulina, 2004. pg. 160-180.

KOZEL, Salete. Comunicando e representando: mapas como construções socioculturais. In: SEEMANN, Jörn (org.). A aventura cartográfica: perspectivas, pesquisas e reflexões sobre a cartografia humana. Fortaleza: Expressão Gráfica e Editora, 2005. p. 131-149.

KOZEL, Salete. Mapas mentais - uma forma de linguagem: perspectivas metodológicas. In: KOZEL, S. [et al] (orgs.). Da percepção e cognição a representação: reconstrução teóricas da Geografia Cultural e Humanista. São Paulo: Terceira Margem; Curitiba: NEER, 2007. p. 114-138.

LACOSTE, Yves. A Geografia - isso serve, em primeiro lugar, para fazer a guerra. Tradução Maria Cecília França. Campinas: Papirus, 1988.

MASSEY, Doreen B. Pelo espaço: uma nova política da espacialidade. Tradução: Hilda Pareto Maciel, Rogério Haesbaert. Rio de Janeiro: Bertand Brasil, 2008.

MOREIRA, Rui. Pensar e ser em geografia: ensaios de história, epistemologia e ontologia do espaço. São Paulo: Contexto, 2007.

OLIVEIRA, Livia de. Estudo Metodológico e Cognitivo do Mapa. Tese de Livre-Docência. Universidade de São Paulo, São Paulo, 1978.

PAGANELLI, Tomoko Iyda. Para a construção no espaço geográfico na criança. Dissertação de Mestrado. Fundação Getúlio Vargas, Rio de Janeiro, 1982.

PASSINI, Elza Yasuko. Os gráficos em livros didáticos de Geografia de $5^{\text {a }}$ série: seu significado para alunos e professores. Tese de Doutorado. Universidade de São Paulo, São Paulo, 1996.

PINHEIRO, José Q. Mapas cognitivos do mundo: representações mentais distorcidas? In: SEEMANN, Jörn (org.). A aventura cartográfica: perspectivas, pesquisas e reflexões sobre a cartografia humana. Fortaleza: Expressão Gráfica e Editora, 2005. p. 151-169.

SANTOS, Douglas. A reinvenção do espaço: diálogos em torno da construção do significado de uma categoria. São Paulo: UNESP, 2002.

SANTOS, Milton. Por uma Geografia Nova: da crítica da Geografia a uma Geografia crítica. São Paulo: HUCITEC, 1978.

SEEMANN, Jörn. Mapas, mapeamentos e a cartografia da realidade. Revista Geografares. No. 04. Vitória: EDUFES, 2003. Pg. 49-60.

SIMIELLI, Maria Elena Ramos. O mapa como meio de comunicação: implicações no ensino da Geografia do $1^{\circ}$ grau. Tese de Doutorado. Universidade de São Paulo, São Paulo, 1986.

TEIXEIRA, Salete Kozel. Das imagens às linguagens do geográfico: Curitiba, a "capital ecológica". Tese de Doutorado. São Paulo, 2001.

VIGOTSKI, Lev Semenovich. A construção do pensamento e da linguagem. Tradução: Paulo Bezerra. São Paulo: Martins Fontes, 2000.

Trabalho enviado em setembro de 2010 Trabalho aceito em dezembro de 2010 